\title{
PEMANFAATAN Web App BUILDER UNTUK PEMBUATAN SISTEM INFORMASI JALAN DAN JEMBATAN BERBASIS WEB SIG (Studi Kasus : Kabupaten Sumba Tengah)
}

\author{
Togi H Nainggolan ${ }^{1}$, Abraham Lomi ${ }^{2}$, dan Silvester Sari Sai ${ }^{3}$ \\ ${ }^{1}$ Jurusan Teknik Sipil, ITN Malang, Jl. Bendugnan Sigura-gura No.2 \\ Email: togihnainggolan@lecturer.itn.ac.id \\ 2 Jurusan Teknik Elektro, ITN Malang, Jl. Bendugnan Sigura-gura No.2 \\ Email: abraham@lecturer.itn.ac.id \\ ${ }^{3}$ Prodi Teknik Geodesi, ITN Malang, Jl. Bendugnan Sigura-gura No.2 \\ Email: silvester@lecturer.itn.ac.id
}

\begin{abstract}
ABSTRAK
Kelancaran transportasi merupakan hal yang sangat penting dalam memajukan perekonomian suatu daerah khususnya dalam mendukung kelancaran pergerakan orang ataupun barang dari satu tempat ke tempat lain. Kabupaten Sumba Tengah sebagai salah satu Kabupaten di Provinsi Nusa Tenggara Timur memiliki potensi daerah yang beragam dan membutuhkan akses transportasi untuk mendukung kegiatan pembangunan agar dapat berjalan dengan baik. Kendala yang terjadi terkait tranportasi adalah belum tersedianya data dan informasi dalam bentuk digital yang dapat diakses dengan mudah dan cepat untuk mendukung sistem pengambilan keputusan khususnya dalam pemeliharaan sarana transportasi jalan dan jembatan. Tujuan penelitian ini memiliki fokus untuk membuat sebuah aplikasi yang dapat menyampaikan informasi dalam bentuk WebSIG. WebSIG merupakan metode untuk meyampaikan informasi peta dalam bentuk digital mengunakan layanan internet yang memungkinkan pengguna untuk melakukan interaksi dengan server. Sistem informasi jaringan jalan dan jembatan Kabupaten Sumba Timur dilakukan menggunakan arsitektur WebSIG dengan pendekatan thick client dan client side yang terdiri atas komponen web server, map server, map application dan database server dengan dukungan perangkat lunak Web App Builder dan PostgreSQL database. Hasil dari kegitan ini berupa perangkat lunak WebSIG yang memberikan informasi jaringan jalan dan jembatan berdasarkan Peraturan Menteri Pekerjaan Umum dan Perumahan Rumah Rakyat Nomor 25/PRT/M/2014 Tentang Penyelengaraan Data dan Informasi Geospasial Infrastruktur Bidang Pekerjaan Umum dan Perumahan Rakyat. Total panjang ruas jalan kabupaten di Kabupaten Sumba Tengah adalah $750.92 \mathrm{Km}$ dengan Jumlah ruas jalan sebanyak 139 ruas dan Jumlah jembatan 73 jembatan. Perangkat lunak Web SIG memiliki fungsi pencarian data berdasarkan atribut yang dimiliki dan fungsi mengubah data vektor dan atribut.
\end{abstract}

Kata kunci: Jalan,Jembatan,Web App Builder,WebSIG

\section{PENDAHULUAN}

Pemanfaatan data geospasial (DG) dan informasi geospasial (IG) saat ini semakin banyak digunakan dalam kegiatan perencanaan, pelaksanaan, pengendalian dan evaluasi pelaksanaan pembangunan yang berkelanjutan. Hadirnya Undang-Undang Nomor 4 Tahun 2011 tentang Informasi Geospasial dan Rencana Kerja Pemerintah (RKP) Tahun 2017 semakin menguatkan peran DG dan IG dalam pelaksanaan kegiatan pembangunan di Indonesia. Salah satu tujuan dari Undang-Undang Informasi Geopasial adalah mendorong penggunaan IG dalam penyelenggaraan pemerintahan dan dalam berbagai aspek kehidupan. Dalam konteks penyelengaraan pemerintahan terkait kegiatan pembangunan wilayah, DG dan IG dapat digunakan sebagai alat bantu dalam perumusan kebijakan, pengambilan keputusan, dan/atau pelaksanaan kegiatan yang berhubungan dengan ruang kebumian. RKP 2017 sebagai bentuk penjabaran Rencana Pembangunan Jangka Menengah Nasional (RPJMN) 2015-2019, RKP 2017 disusun dengan pendekatan holistik-tematik, integratif, dan spasial dalam upaya pencapaian sasaran agenda prioritas nasional agar dapat berjalan lebih efektif dan efisien.

Selaras dengan perencanaan pembanguan nasional yang melibatkan unsur spasial, selanjutnya pengumpulan dan pengelolaan data spasial atau geospasial dilaksanakan oleh berbagai instansi pemerintahan baik di tingkat kementerian hingga organisasi perangkat daerah (OPD). Peraturan Menteri Pekerjaan Umum dan Perumahan 


\section{JURNAL INFOMANPRO}

Rumah Rakyat Nomor 25/PRT/M/2014 Tentang Penyelengaraan Data dan Informasi Geospasial Infrastruktur Bidang Pekerjaan Umum dan Perumahan Rakyat memiliki beberapa ruang lingkup diantaranya terkait dengan prosedur penyelenggaraan data dan informasi geospasial infrastruktur serta kodefikasi dan format isian data infrastruktur. Salah satu unsur infrastruktur yang diatur adalah terkait dengan standar kodifikasi data dasar infrastruktur unsur Bina Marga yang meliputi obyek jalan dan jembatan. Terdapat 2 hal yang penting dalam peraturan tersebut, pertama terkait dengan tata cara pegumpulan data geospasial dan kedua penyimpanan data dalam bentuk geodatabase. Hal lainnya yang diatur dalam peraturan tersebut adalah terkait dengan pencetakan peta atau publikasi digital. Publikasi digital dari data geopasial dapat dilakkuan salah satunya melalui layanan internet yaitu web.

Kelancaran infrasruktur transportasi merupakan hal yang sangat penting dalam memajukan perekonomian suatu daerah khususnya dalam mendukung kelancaran pergerakan orang ataupun barang dari satu tempat ke tempat lain. Kabupaten Sumba Tengah sebagai salah satu Kabupaten di Propinsi Nusa Tenggara Timur memiliki potensi daerah yang beragam dan membutuhkan akses transportasi untuk mendukung kegiatan pembangunan agar dapat berjalan dengan baik. Kendala yang terjadi terkait tranportasi adalah belum tersedianya data dan informasi dalam bentuk digital yang dapat diakses dengan mudah dan cepat untuk mendukung sistem pengambilan keputusan khususnya dalam pemeliharaan infrasruktur transportasi jalan dan jembatan. Tujuan penelitian ini memiliki fokus untuk membuat sebuah aplikasi yang dapat menyampaikan informasi dalam bentuk Web SIG dari data jalan dan jembatan. Web SIG dibangun menggunakan Web App builder boundless yang bersifat opensource dan shareware dengan konektivitas basis data menggunakan perangkat lunak PostgreSQL. Hasil penelitian dini diharapkan dapat diterapkan olhe SKPD terkait dalam proses pengambilan keputusan dalam proses perencanaan revitalisasi infrasruktur transportasi jalan dan jembatan.

\section{DATA GEOSPASIAL DAN WEBSIG}

Data Geospasial yang selanjutnya disingkat DG adalah data tentang lokasi geografis, dimensi atau ukuran, dan/atau karakteristik objek alam dan/atau buatan manusia yang berada di bawah, pada, atau di atas permukaan bumi. Untuk memperoleh data geospasial dilakukan kegiatan survei pemetaan yang dapat dilakukan dengan metode survei terestris maupun ekstraterestris. Berdasarkan Permen PUPR Nomor 25/PRT/M/2014 kegiatan survei akusisi data geospasial dapat dilakukan menggunakan peralatan Global Positioning System (GPS) tipe Navigasi atau Geodetik. GPS Geodetik digunakan dalam proses pengukuran titik Ground Control Point (GCP) dan Identified Conrol Point (ICP) dalam proses ortorektifikasi citra satelit resolusi tinggi (CSRT). CSRT selanjutnya digunakan sebagai peta dasar untuk proses pembuatan peta tematik lainnya atau untuk proses analisis. Data geospasial yang telah diolah selanjutnya disebut sebagai informasi geospasial atau IG dapat diturunkan menjadi informasi geospasial yang memuat 1 (satu) tema yang disebut sebagai informasi geospasial tematik atau IGT. Data geospasial infrasruktur tranportasi jalan dan jembatan yang telah diolah merupakan salah satu bentuk dari IGT. Hasil akusisi data dan data yang telah diolah disimpan dalam bentuk basis data spasial atau geodatabase dan dapat dipublikasikan melalui layanan web atau web service.

Web SIG merupakan perkembangan dari teknologi Sistem Informasi Geografis (SIG) yang mengubah pendekatan dari visualisasi peta digital berbasiskan desktop ke sistem berbasiskan layanan internet yaitu web. Peta merupakan data geospasial sebagai cara terbaik untuk memperlihatkan kondisi ruang di sekitar kita dan internet menyediakan cara tercepat untuk melakukan akses terhadap peta dibandingkan dengan cara konvensional (Kraak 2004; Tanfara \& Tutić 2007). Kebutuhan akan berbagi informasi mengubah media yang digunakan untuk saling berbagi informasi seperti yang terlihat pada Gambar 1. Web SIG sendiri dapat diartikan sebagai sarana komunikasi data dan informasi antara pengguna (user/client) dengan server menggunakan peta atau data geospasial yang dihasilkan melalui proses kartografi dan SIG dengan bantuan internet khsusnya world wide web. Terdapat beberapa unsur penting dari konsep Web SIG yaitu berbagai data dan informasi geospasial, sistem informasi geografis dan Web. Web SIG memungkinkan pengguna dapat melakukan komunikasi dan berbagi data geospasial menggunakan layanan internet yaitu web. Web adalah salah satu layanan TCP/I yang paling populer dalam memberikan kemudahan informasi (Hartanto,2002). Web SIG menjadi cara termudah dan cepat untuk melakukan diseminasi dan geopasial dengan dukungan tool pengelolaan data (Alesheikh et al. 2002). Pemanfaatan Web sebagai salah satu layanan internet memberikan perbedaan antara internet SIG dan Web SIG. Web SIG merupakan kombinasi dari layanan internet yaitu Web dan SIG. Internet SIG memiliki cakupan yang lebih luas dibandingkan dengan WebSIG. Sebuah sistem ifnormasi yang menggunakan layanan internet berupa web dalam berbagi data dan informasi geospasial dapat dikategorikan sebagai Web SIG. Gambar 2 menunjukkan perbedaan antara internet SIG dan Web SIG. 


\section{JURNAL INFOMANPRO}

p-ISSN 2460-9609

e-ISSN 2774-7956

https://ejournal.itn.ac.id/index.php/infomanpro

vol.6 No 2 Tahun 2021, pp. 27-34

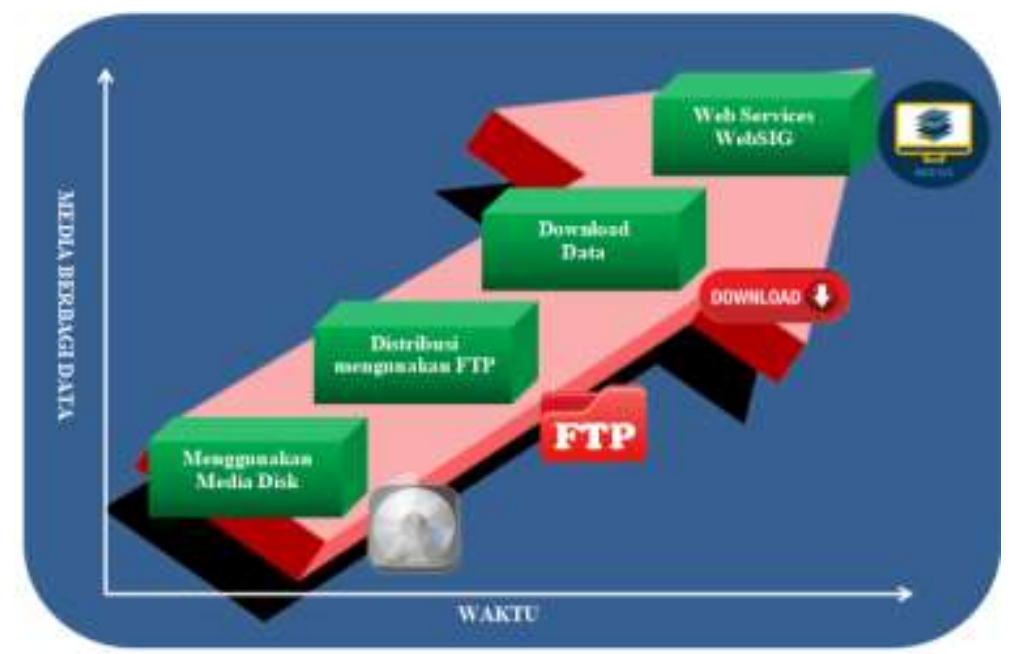

Gambar 1. Perkembangan media berbagi data dan informasi geospasial

\section{GIS}

\section{Distributed}

GIS

\section{Internet GIS}

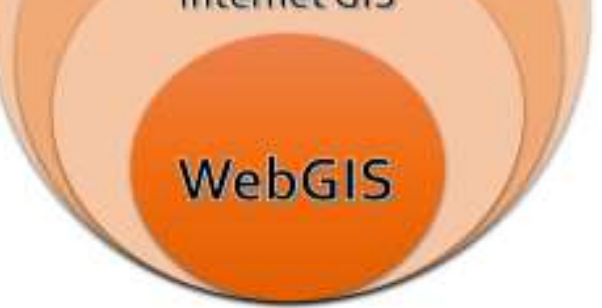

Gambar 2. Perbedaan internet SIG dan Web SIG

Arsitektur Web SIG memiliki 3 (tiga) tingkatan yaitu tingkatan data, tingkatan logika dan tingkatan prsentasi seperti terlihat pada Gambar 3. Pada tingkatan data dibentuk sebuah basis data spasial atau geodatabase yang didukung oleh Relational Database Management System (RDBMS). Fungsi dari tingkatan data adalah manajemen basis data yang berfungsi untuk mengakses, menyimpan, serta memodifikasi data geospasial dan atribut yang ada. Pada tingkatan logika dilakukan proses logika atau perhitungan dari data geospasial. Pada tingkatan logika menggunakan perangkat lunak yang mendukung aplikasi layanan web map service (WMS) dan web feature service (WFS). Pada tingkatan presentasi merupakan tampilan antar muka pada sisi client yang terdiri atas berbagai konten yang dibutuhkan oleh pengguna dalam mengakses data dan informasi geodatabase melalui software atau webbrowser. Pada tingkatan ini disebut juga sebagai bagian front-end dalam pemrograman WebSIG.
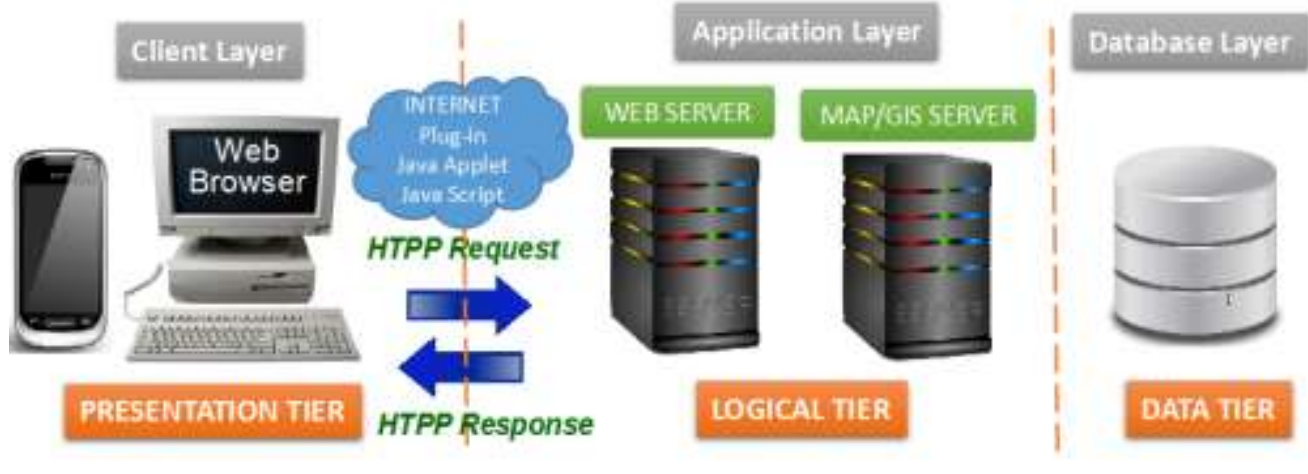

Gambar 3. Arsitektur Web SIG 


\section{JURNAL INFOMANPRO p-ISSN 2460-9609 e-ISSN 2774-7956}

https://ejournal.itn.ac.id/index.php/infomanpro vol.6 No 2 Tahun 2021, pp. 27-34

\section{METODOLOGI PENELITIAN}

Tahapan kegiatan penelitian pembuatan program aplikasi sistem informasi jalan dan jembatan menggunakan Web App Builder terdiri atas survei geometrik dan kondisi jalan dan jembatan, penyusunan database relasional atau relational database management system (RDBMS) menggunakan perangkat lunak Postgre SQL, pembuatan tampilan peta dinamis menggunakan perangkat lunak aplikasi Web App Builder Boundless yang terintegrasi dengan Quantum GIS (QGIS), dan pengaturan di dalam web server menggunakan perangkat lunak XAMPP. Kegiatan survei lapangan dilakukan di wilayah mitra penelitan di Kabupaten Sumba Tengah - Provinsi Nusa Tenggara Timur.

\section{Survei kondisi jalan dan jembatan}

Pelaksanaan survei lapangan dilakukan oleh tim survei peneliti didampingi oleh Bidang Bina Marga pada Dinas Pekerjaan Umum dan Penataan Ruang Kabupaten Sumba Tengah. Jumlah ruas jalan dan jembatan yang disurvei sejumlah 139 ruas jalan dengan total panjang adalah 750,962 Km. Jumlah jembatan yang disurvei sejumlah 73 jembatan. Kegiatan survei jalan dan jembatan yang dibagi berdasarkan atribut masing-masing obyek berdasarkan Permen PUPR Nomor 25/PRT/M/2014. Kegiatan survei dilakukan menggunakan peralatan Global Positioning System (GPS) Navigasi, alat ukur jarak dan alat pendukung. Survei jalan dilakukan untuk mengetaui posisi awal dan akhir ruas jalan seperti terlihat pada Gambar 4, kondisi dan tipe perkerasan jalan serta kondisi jembatan seperti terlihat pada Gambar 5.

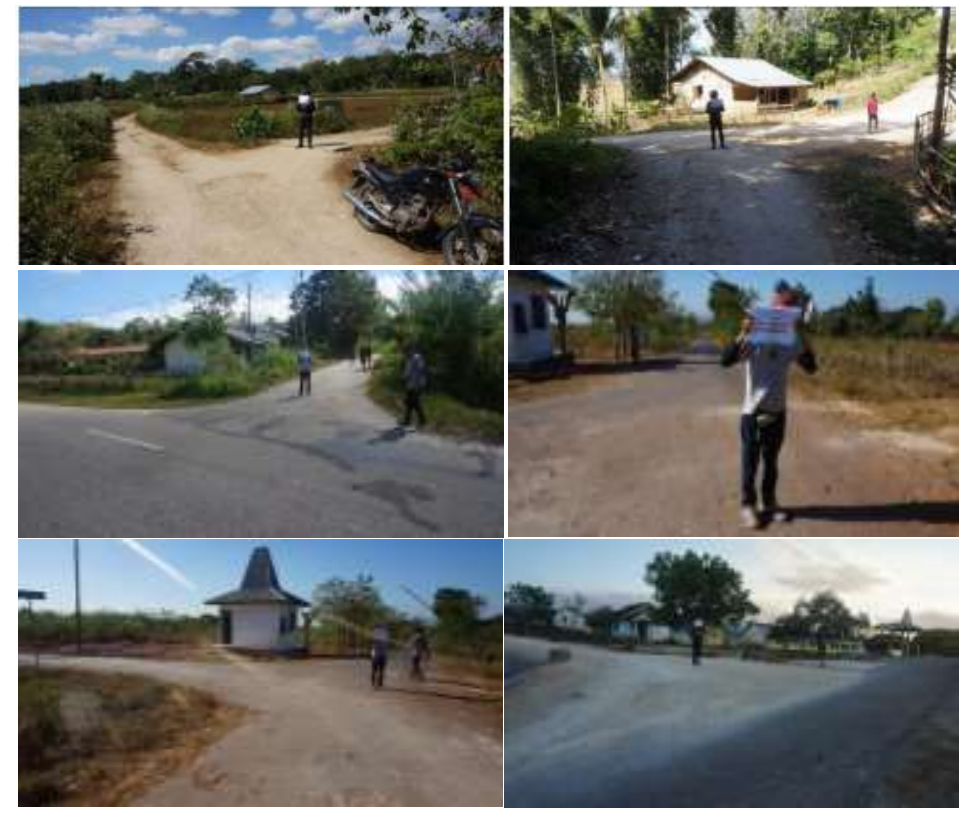

Gambar 4. Dokumentasi survei awal dan akhir ruas jalan

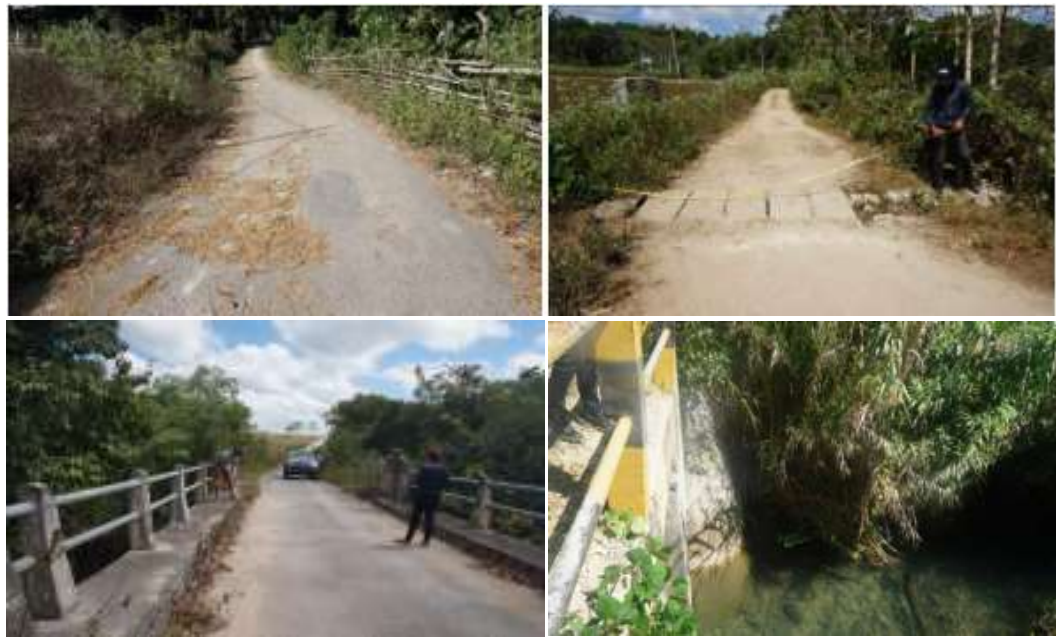

Gambar 5. Dokumentasi survei kondisi jalan dan jembatan 
JURNAL INFOMANPRO

p-ISSN 2460-9609

e-ISSN 2774-7956

https://ejournal.itn.ac.id/index.php/infomanpro

vol.6 No 2 Tahun 2021, pp. 27-34

\section{Penyusunan basis data relasional jalan dan jembatan}

Penyusunan basis data geospasial atau geodatabase dilakukan menggunakan perangkat lunak PostgreSQL/PostGIS. Hubungan antara entitas basis data geospasial yang diperoleh dari hasil survei jalan dan jembatan di lokasi mitra disusun dalam bentuk skema relasi seperti tersaji pada Gambar 6. Terdapat 5 (lima) entitas utama dalam pembentukkan geodatabase yaitu meliputi Entitas Adminisrasi, Entitas Jalan, Entitas Perkerasan Jalan, Entitas Kondisi Jalan, Entitas Jembatan. Untuk tiap entitas memiliki kunci identifikasi (primary key) yaitu kolom data GID yang unik untuk masing-masing entitas. Penyusunan entitas data dan kolom atribut data disesuaikan dengan kodefikasi dan format isian data infrastruktur berdasarkan Permen PUPR Nomor 25/PRT/M/2014 (Nainggolan, TH dkk,2019). Selanjutnya diagram relasi yang terbentuk disusun dalam perangkat lunak PosrgreSQL meliputi pembuatan skema dan tabel entitas seperti terlihat pada Gambar 6 dan 7.

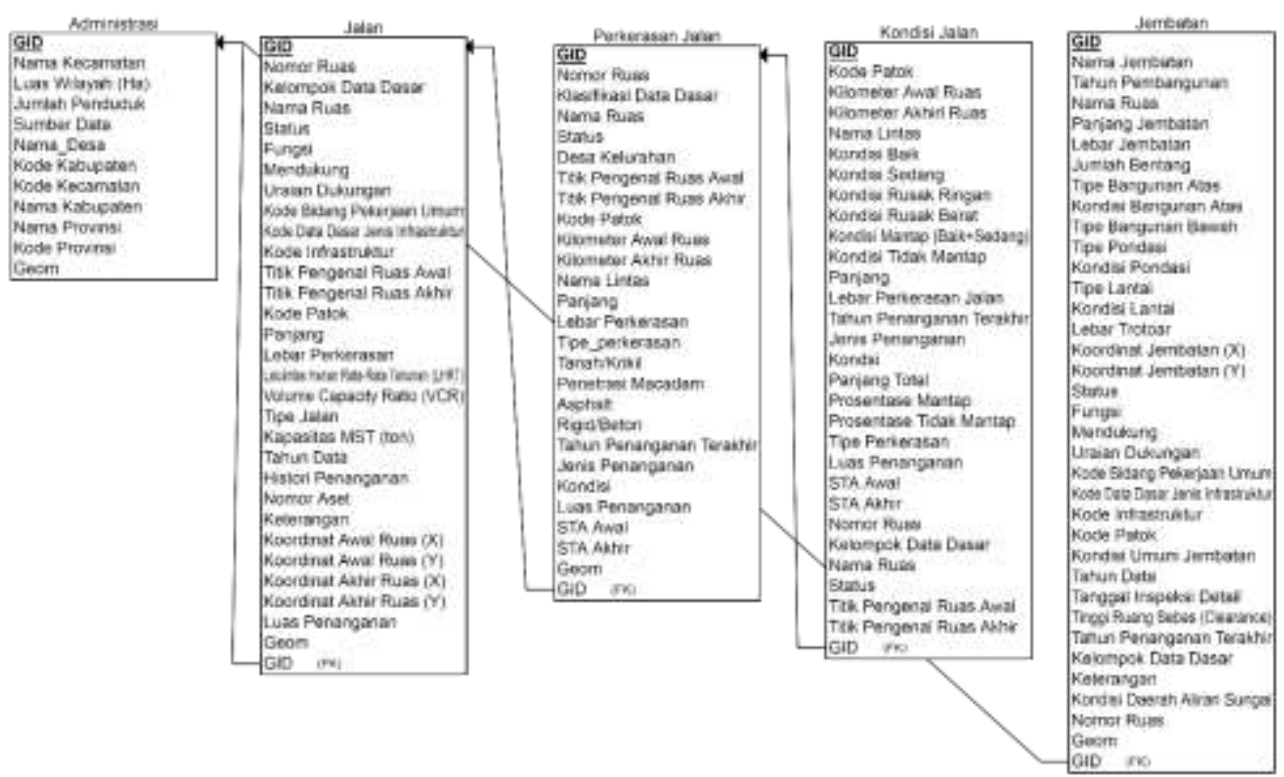

Gambar 6. Relasi skema geodatabase dari entitas data jalan dan jembatan

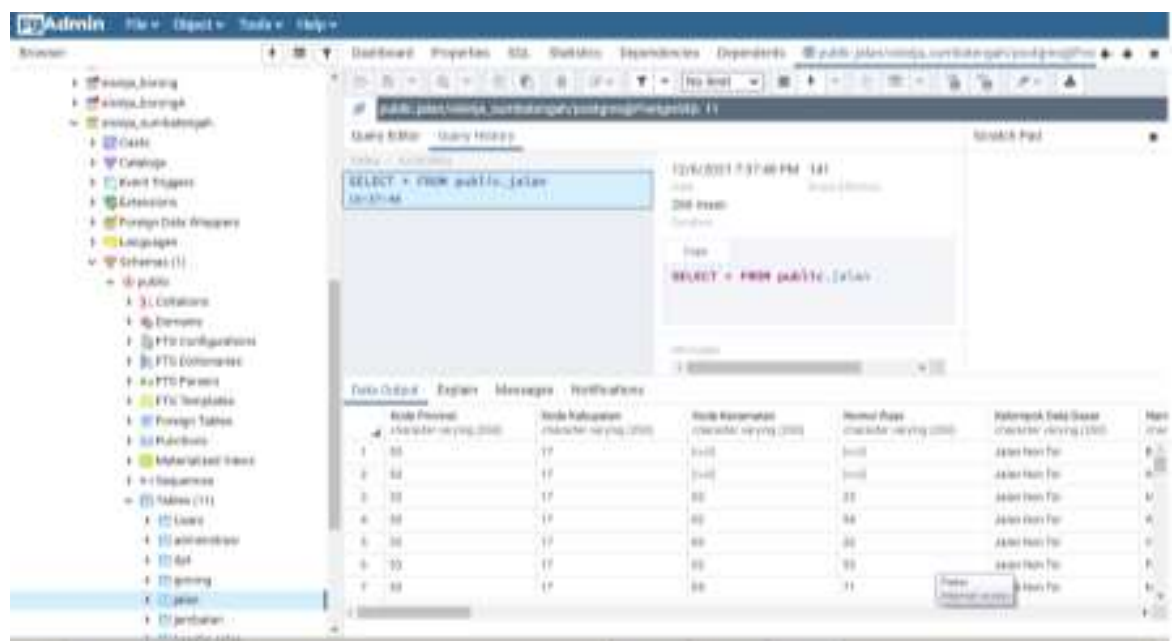

Gambar 7. Pembuatan skema dan tabel entitas dari informasi jalan dan jembatan di perangkat lunak PostgreSQL

\section{Pembuatan tampilan Web SIG menggunakan Web App Builder Boundless}

Pembuatan tampilan peta digital Web SIG dilakukan menggunakan perangkat lunak Web App Builder Boundless. Boundless Web App Builder merupakan plugins dari perangkat lunak QGIS. Untuk melakukan desain Web SIG Sistem Informasi Jaringan Jalan dan Jembatan Kabupaten Sumba Tengah terlebih dahulu melakukan koneksi basis data geospasial yang telah dibuat menggunakan PosgreSQL seperti terlihat pada Gamba 8. Selanjuntya dilakukan 


\section{JURNAL INFOMANPRO}

https://ejournal.itn.ac.id/index.php/infomanpro vol.6 No 2 Tahun 2021, pp. 27-34

pengaturan tampilan peta digital melalui form boundless Boundless WebSDK seperti terlihat pada Gambar 9. Peta digital Web SIG dibuat dalam bentuk layer data dengan format GeoJson yang merupakan JavaScript Object Notation. Program aplikasi peta yang digunakan dalam Web App Builder menggunakan open layer yang berbasiskan java script.
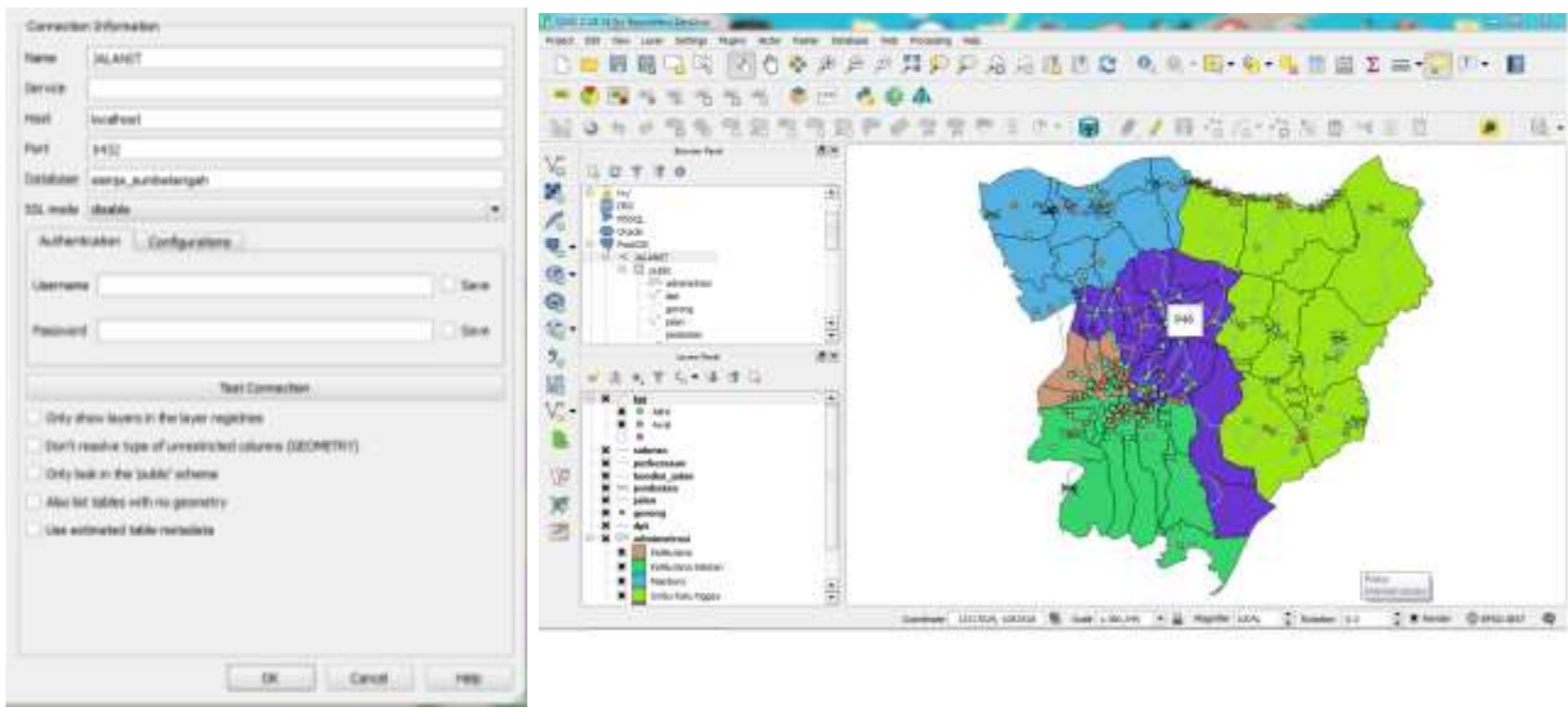

Gambar 8. Koneksi geodatabase Postgre SQL dan QGIS



Gambar 9. Pengaturan peta digital Web SIG menggunaka Boundless Web App Builder

\section{Koneksi Web SIG ke Web server menggunakan xampp}

Program aplikasi Web SIG sistem informasi jalan dan jembatan Kabupaten Sumba Tengah ditempatkan di server localhost terlebih dahulu untuk melakukan uji coba fungsionalitas dari Web SIG. Untuk menjalankan program aplikasi dalam server localhost menggunakan web server XAMPP. Pembuatan halaman utama atau front-end dari Web SIG sistem informasi jalan dan jembatan menggunakan bahasa pemrograman PHP dengan dukungan Cascading Style Sheets (CSS). Tampilan dari halaman utama Web SIG sistem informasi jaringan jalan Kabupaten Sumba Tengah seperti terlihat pada Gambar 10. Halaman peta dari program aplikasi ini seperti terlihat pada Gambar 11, program aplikasi Web SIG ini juga dilengkapi dengan fasilitas pencarian data atau query berdasarkan atribut yang dimiliki oleh masing-masing tabel data seperti terlihat pada Gambar 12. Fasilitas lainnya yang terdapat pada perangkat lunak Web SIG ini adalah penambahan data spasial dan editing data spasial dan atribut. Editing data spasial dan atribut juga dapat dilakukan menggunakan perangkat lunak QGIS yang terkoneksi dengan geodatabase yang terdapat pada PostgreSQL. 


\section{JURNAL INFOMANPRO}

p-ISSN 2460-9609

e-ISSN 2774-7956

https://ejournal.itn.ac.id/index.php/infomanpro

vol.6 No 2 Tahun 2021, pp. 27-34

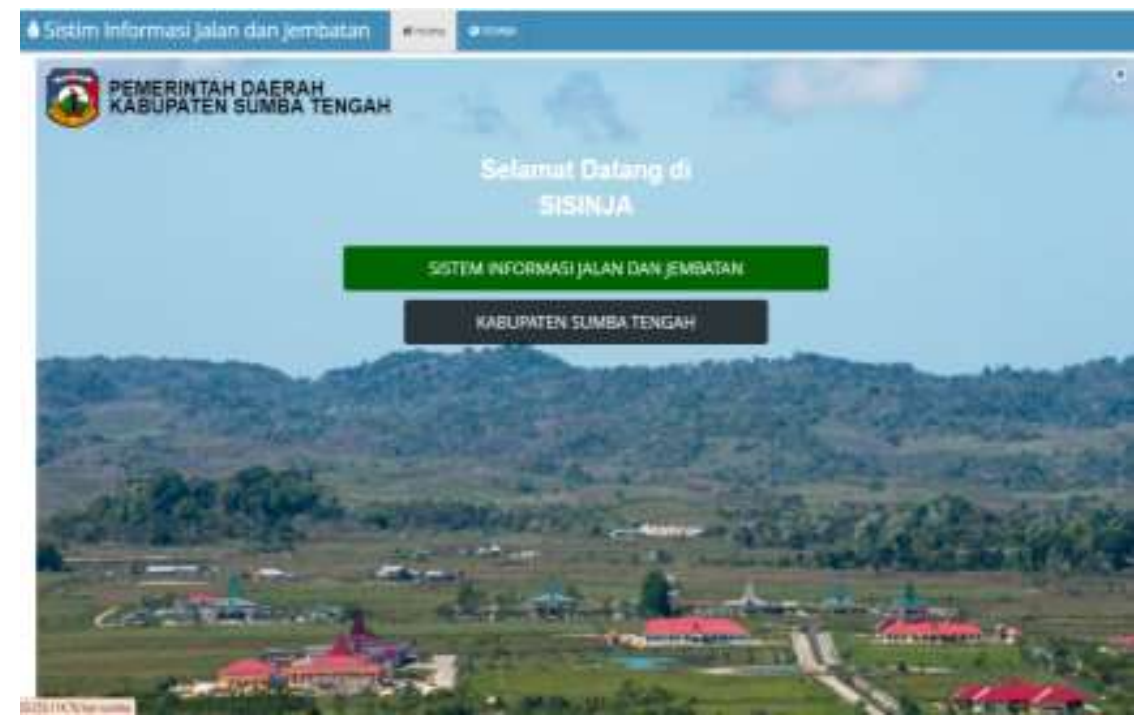

Gambar 10. Tampilan halaman utam Web SIG sistem informasi jalan dan jembatan Kabupaten Sumba Tengah

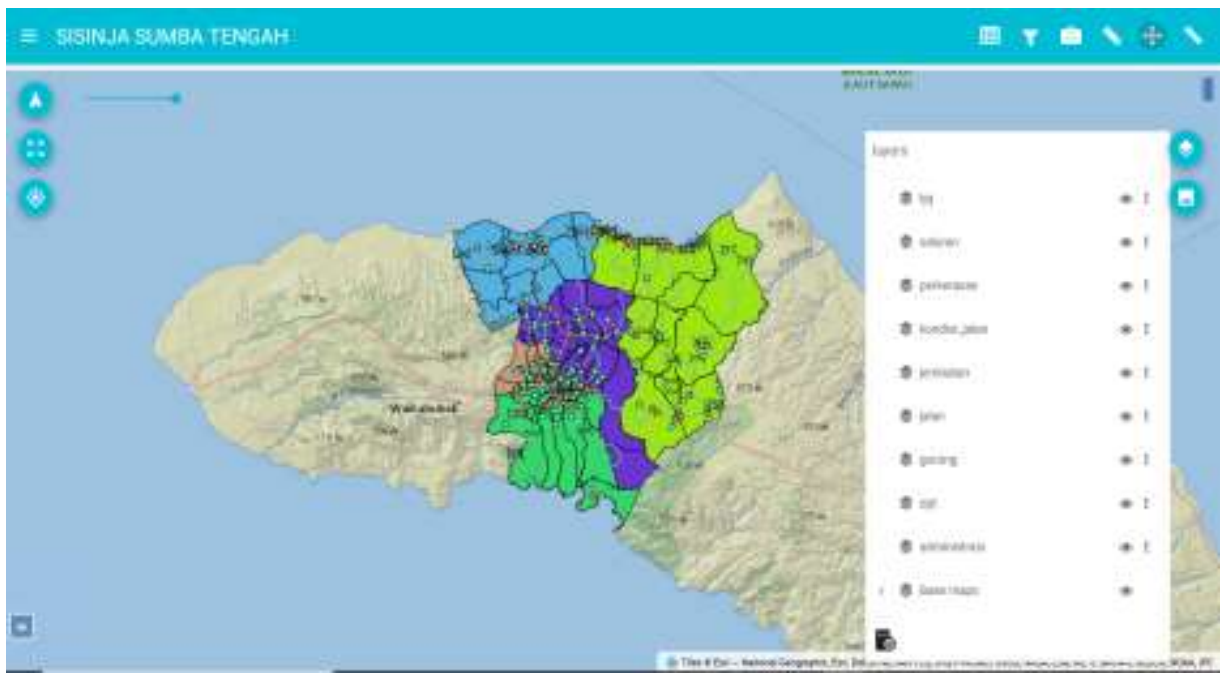

Gambar 11. Tampilan halaman peta Web SIG sistem informasi jalan dan jembatan Kabupaten Sumba Tengah

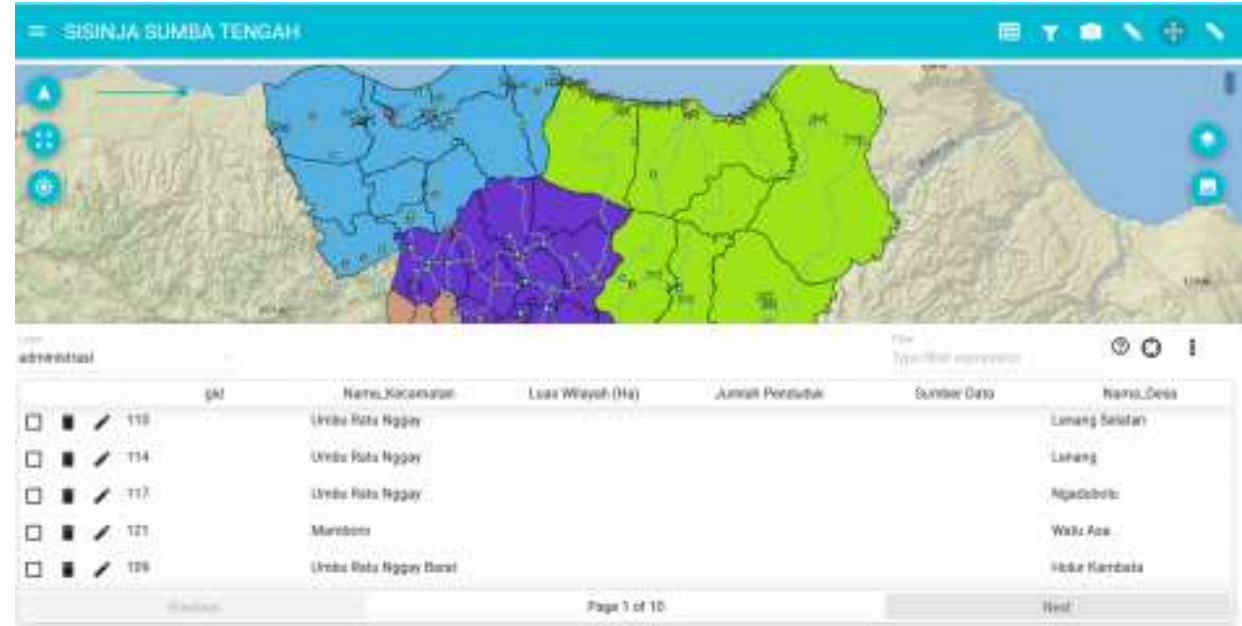

Gambar 12. Tampilan form query atribut Web SIG sistem informasi jalan dan jembatan Kabupaten Sumba Tengah 
JURNAL INFOMANPRO

\section{KESIMPULAN}

Berdasarkan hasil penelitian yang telah dilaksanakan terdapat beberapa kesimpulan sebagai berikut :

1. Jumlah ruas jalan dan jembatan Kabupen Sumba Tengah yang disurvei adalah sejumlah 139 ruas jalan dengan total panjang 750,962 Km. Jumlah jembatan yang disurvei sejumlah 73 jembatan.

2. Klasifikasi kondisi jalan dengan kondisi baik sepanjang 225,024 Km (29,96\%), kondisi sedang sepanjang 62,672 $\mathrm{Km}(8,35 \%)$, kondisi rusak ringan sepanjang 42,480 Km (5,66\%) dan kondisi rusak berat sepanjang 420,757 Km $(56,03 \%)$. Klasifikasi berdasarkan tipe perkerasan jalan dengan tipe perkerasan tanah/kerikil/telford/macadam adalah 355,134 km (47,29\%), tipe perkerasan lapisan penetrasi macadam (lapen) adalah 311,505 $\mathrm{Km}(41,75 \%)$, tipe perkerasan aspal adalah 80,876 Km (10,77\%), tipe perkerasan rigid/beton adalah 1,447 Km $(0,19 \%)$.

3. Tipe bangunan atas jembatan yaitu beton bertulang (BBT) sejumlah 69 unit, dengan kondisi baik sejumlah 43 unit, kondisi sedang 21 unit dan kondisi rusak ringan sejumlah 5 unit. Tipe bangunan atas jembatan dengan rangka baja (RBJ) sejumlah 3 unit dengan kondisi baik sejumlah 2 unit dan kondisi sendag sejumlah 1 unit. Tipe bangunan atas jembatan dengan rangka rangka kayu sejumlah 1 buah, dengan kondisi sedang.

4. Pembuatan program aplikasi Web SIG sistem informasi jaringan jalan dan jembatan Kabupaten Sumba Tengah dapat dilakukan menggunakan Web App Builder Boundless dengan dukungan Boundless Web SDK yang memberikan fungsionalitas yang cukup baik dalam penyimpanan data, editing data, pencarian data dan dukungan visualisasi yang menarik.

5. Arsitektur Web SIG sistem informasi jalan dan jembatan Kabupaten Sumba Tengah telah menggunakan tiga tingkatan (tier level) yaitu tingkatan database, tingkatan logika dan tingkatan presentasi dengan dukungan perangkat lunak open source.

\section{DAFTAR PUSTAKA}

Alesheikh A, Helali H, Behroz H.(2002). Web GIS: Technologies and its applications. In: Symposium on Geospatial Theory, Processing and Applications, Ottawa.

B. Linden, S. Foord, Q. J. B. Horta-Lacueva, and P. J. Taylor, "Bridging the gap: How to design canopy bridges for arboreal guenons to mitigate road collisions," Biological Conservation, vol. 246, p. 108560, Jun. 2020, doi: 10.1016/j.biocon.2020.108560.

F. Sagberg, R. Elvik, and P. A. Langeland, "Crash risk on entrance versus exit zones of road bridges in Norway," Accident Analysis \& Prevention, vol. 134, p. 105247, Jan. 2020, doi: 10.1016/j.aap.2019.07.023.

Hartanto,A.A.,Purbo,O. (2002). Teknologi e-Learning berbasis PHP dan MySQLT Elex Media Komputindo Kelompok Gramedia, Jakarta.

Kraak,M.J. (2004). The role of the map in a Web-GIS environment. Journal of Geographical Systems 6(2): 83-93.

Nainggolan,TH., Sembayang,N., Sai,S.S. (2019). Sistem Informasi Database Jalan dan Jembatan Kabupaten Sumba Tengah Provinsi Nusa Tenggara Timur. SEMSINA infrasruktur Berkelanjutan Era Revolusi Industri 4.0. IX9 - IX 16. Malang.

Peraturan Menteri Pekerjaan Umum dan Perumahan Rakyat Nomor 25/PRT/M/2014 tentang Penyelenggaraan Data Dan Informasi Geospasial Infrastruktur Bidang Pekerjaan Umum Dan Perumahan Rakyat. Lembaran Negara RI Tahun 2015 Nomor 48. Kementrian Pekerjaan Umum.

Peraturan Presiden Republik Indonesia Nomor 45 Tahun 2016 tentang Rencana Kerja Pemerintah Tahun 2017. Lembaran Negara RI Tahun 2016 Nomor 95. Sekretariat Negara. Jakarta.

Undang-Undang Nomor 4 Tahun 2011 tentang Informasi Geospasial. Lembaran Negara RI Tahun 2011 Nomor 49, Tambahan Lembaran RI Nomor 5214. Sekretariat Negara. Jakarta. 